Gut, 1988, 29, 101-107

Liver and biliary

\title{
Young $v$ adult cirrhotics: a prospective, comparative analysis of the clinical profile, natural course and survival
}

\author{
S K SARIN, S CHARI, K R SUNDARAM, R K AHUJA, B S ANAND, \\ AND S L BROOR
}

From the Department of Gastroenterology, GB Pant Hospital and Department of Bio-statistics, All India Institute of Medical Sciences, New Delhi, India

SUMMARY In order to assess the frequency and profile of cirrhosis in the young, 169 consecutive patients with cirrhosis were studied. Sixty three $(37 \%)$ patients of $\leqslant 35$ years age were defined as young and the remaining $106(63 \%)$ patients ( $>35$ years) as adult cirrhotics. Men predominated significantly $(p<0.01)$ in the young cirrhotic group. The aetiology, the frequency of positive hepatitis B markers and initial clinical presentation were similar in the two groups. During the follow up period (30.6 \pm 29.7 months for the young and $25.8 \pm 21.7$ months for the adult group), except for abdominal distension and pedal oedema which occurred significantly more often in the adult compared with the young cirrhotics, no difference was noted in the two groups. Twenty seven $(39.7 \%)$ deaths $(40 \%$ as a result of hepatic failure and $52 \%$ due to variceal bleeding) occurred in the young and $47(44.3 \%)$ deaths $(63.8 \%$ because of hepatic failure and $26 \%$ because of variceal bleeding) occurred in the adult cirrhotics during the follow up (difference NS). The five year survival $(61.9 \% \vee 55.7 \%)$ and the probability of survival within the same Child's grade of liver disease were comparable. In both the groups, however, the probability of survival was significantly higher in Child's A compared with Child's B and C and in Child's B compared with Child's C grade of liver disease. Survival was not influenced by sex of the patient and aetiology of cirrhosis. Results of this prospective study indicate that cirrhosis is not uncommon in young adults. The aetiology, clinical presentation, natural history of the disease and the survival rates in young cirrhotics do not differ significantly from adult cirrhotics.

It is generally believed that cirrhosis occurs much less frequently in young adults than in older patients. A number of reports from the West indicate that less than $5 \%$ of cirrhotics are under 35 years of age. ${ }^{1-5}$ Similarly, in a large study from Japan, the incidence of cirrhosis in patients below 30 years, was close to that reported from the West. ${ }^{6}$ It has been suggested that this is because alcohol related cirrhosis which is

Address for correspondence: Dr S K Sarin, Associate Professor, Department of Gastroenterology, GB Pant Hospital, New Delhi - 110002 , India.

Received for publication 2 July 1987. the commonest cause of cirrhosis in the West, occurs in the older age group patients. In a recent study of young drug abusers, however, $43 \%$ of the cirrhotics were below the age of 35 years. ${ }^{7}$ Limited information was provided on the clinical presentation and survival rates of these patients. In fact, it is because of its alleged rarity that little attention has been paid to studying the frequency and significance of hepatitis B virus (HBV) positivity and the profile of cirrhosis in young adults. The aim of the present study was to determine and compare the relative frequency, natural course and survival rates in young and adult cirrhotic patients. 
Methods

PATIENTS

One hundred and sixty nine consecutive patients with cirrhosis of liver seen between February 1983 and December 1985 were included in the study. Patients were arbitrarily divided in two groups as suggested by Yoshida et $a l^{7}$ (a) young cirrhotics (age $\leqslant 35$ years) (b) adult cirrhotics (age $>35$ years). As our department looks after only adults, patients below the age of 10 years could not be included in this analysis. The diagnosis of cirrhosis was made either by histopathology (young cirrhotics - 51 and adult cirrhotics 86 patients) or at laparoscopy (young cirrhotics eight and adult cirrhotics - 10 patients). In the remaining 14 patients, liver biopsy could not be done because of various reasons. In these patients, the diagnosis of cirrhosis was made on the basis of clinical features and endoscopic demonstration of oesophageal varices. The diagnosis of alcoholic cirrhosis was made on the basis of history of alcohol consumption and histopathological criteria laid down by the international group. ${ }^{8}$

Sera from patients was stored at $-80^{\circ} \mathrm{C}$ and studied for hepatitis $\beta$ surface antigen (HBsAg), antibody to the surface antigen (anti-HBs) and IgM antibody to the core antigen (IgM anti-HBc) by the ELISA technique, using commercially available kits (Abbott Laboratories, North Chicago, Illionis, USA). With the detection of HBsAg or anti-HBs in the serum, a diagnosis of $\mathrm{HBV}$ related cirrhosis was made. ${ }^{9}{ }^{10}$ In the remaining patients (except one patient with Wilson's disease and one with alpha 1 antitrypsin deficiency), where no definite aetiological agent could be identified, a diagnosis of cryptogenic cirrhosis was considered. For the purpose of clear presentation, patients with $\mathrm{HBV}$ related cirrhosis, cryptogenic cirrhosis, Wilson's disease, and alpha 1 antitrypsin deficiency were grouped together as nonalcoholic cirrhosis and were compared with the alcoholic cirrhotics.

ASSESSMENT

The presenting complaints of every patient were recorded in detail in a specially designed 'liver diseases proforma'. The patients were closely followed for the entire period of the study. Various events such as jaundice, ascites, variceal bleeding, death, etc. occurring during follow up were recorded. Assessment of alcohol intake was made with the help of a modified interview schedule. ${ }^{11}$ The severity of liver disease was assessed using Child's criteria ${ }^{12}$ and oesophageal varices were graded from 1-4 according to Conn's classification. ${ }^{13}$ The patients were followed until March, 1986 and the status of the individual patient recorded as alive, lost to follow up, or dead.
STATISTICAL ANALYSIS

All observations are expressed as mean \pm SD. $\chi^{2}$ test with Yates' correction for discrete variables (sex, Child's grade, symptoms, etc), Students $t$ test or nonparametric test (for example, for duration of alcohol consumption) for continuous variables were used for comparing the various parameters between the young and the adult cirrhotic population.

The probability of survival was calculated independently for the young and the adult cirrhotics and for the combined group, after excluding deaths unrelated to cirrhosis, by the life table analysis method. The difference in the probabilities of survival until the end of the follow up period was tested by applying the log rank test. The median survival time was found for both the groups of patients as probability equal to $0 \cdot 5 .^{14}$

\section{Results}

DEMOGRAPHIC PROFILE

Thirty seven per cent ( 63 of 169 ) of our patients were young cirrhotics. Cirrhosis of the liver was seen between 10 and 83 years of age. The mean age of the young cirrhotics was $22 \cdot 8 \pm 7 \cdot 3$ years and that of the adult cirrhotics was $51 \cdot 0 \pm 9 \cdot 2$ years. The mean age of the combined group was $40 \cdot 3 \pm 16 \cdot 4$ years. There were more men than women in the young cirrhotic group, the male to female ratio being $4 \cdot 25: 1$. On the other hand, in the adult cirrhotic population, the male to female ratio was $1 \cdot 26: 1$ (Table 1 ); the difference was statistically significant $(p<0 \cdot 01)$.

\section{AETIOLOGY}

The aetiology of cirrhosis in the two groups of patients is shown in Table 1. One or the other marker of hepatitis $\beta$ virus (HBV) infection was present in $59.7 \%$ of young and $48.1 \%$ of adult cirrhotics (Table $2)$. The incidence of $\mathrm{HBV}$ related and cryptogenic cirrhosis was the same between the two groups (Table 1). The frequency of alcoholic cirrhosis was higher in adults compared with young subjects, but the difference was not significant.

The profile of alcoholic cirrhosis in the two groups of patients is shown in Table 3. Alcoholic cirrhosis was seen only in men in both the groups. The onset of alcohol abuse was seen as early as 14 years of age, with a mean age of $22 \cdot 0 \pm 5.4$ years in the young cirrhotic group. The mean age for young nonalcoholic $(20 \cdot 2 \pm 10.9$ years $)$ cirrhotics was significantly $(p<0 \cdot 01)$ lower than that of alcoholic $(29 \cdot 4 \pm 4 \cdot 1$ years) cirrhotics. In contrast, in the adult group, the mean age for alcoholic (46.5 $\pm 9 \cdot 6$ years) cirrhotics was significantly $(p<0.001)$ lower than the nonalcoholic $(54.4 \pm 4.6$ years $)$ patients. The duration of alcohol consumption, the amount consumed per day 
Table 1 Clinical presentation of young and adult cirrhotic patients

\begin{tabular}{|c|c|c|}
\hline Parameter & $\begin{array}{l}\text { Young cirrhotics } \\
(n=63)\end{array}$ & $\begin{array}{l}\text { Adult cirrhotics } \\
(n=106)\end{array}$ \\
\hline $\begin{array}{l}\text { Mean }( \pm S D) \text { Age (yrs) } \\
\text { Sex (M:F) }\end{array}$ & $\begin{array}{c}22 \cdot 8 \pm 7 \cdot 3 \\
51: 12\end{array}$ & $\begin{array}{c}51 \cdot 7 \pm 9 \cdot 2 \\
59: 47^{*}\end{array}$ \\
\hline \multicolumn{3}{|l|}{ Aetiology } \\
\hline $\begin{array}{l}\text { HBV-related } \\
\text { Alcoholic } \\
\text { Cryptogenic } \\
\text { Wilson's Disease } \\
\alpha-1 \text { anti-trypsin deficiency }\end{array}$ & $\begin{array}{l}32(50 \cdot 8) \dagger \\
10(15 \cdot 9) \\
19(30 \cdot 2) \\
1(1 \cdot 6) \\
1(1 \cdot 6)\end{array}$ & $\begin{array}{r}51(44 \cdot 3) \\
38(35 \cdot 8) \\
21(19 \cdot 8) \\
-\end{array}$ \\
\hline $\begin{array}{l}\text { Child's grade } \\
\text { A } \\
\text { B } \\
\text { C }\end{array}$ & $\begin{array}{l}16(25 \cdot 4) \\
30(47 \cdot 6) \\
17(27 \cdot 0)\end{array}$ & $\begin{array}{l}35(33 \cdot 0) \\
33(31 \cdot 1) \\
38(35 \cdot 9)\end{array}$ \\
\hline $\begin{array}{l}\text { Variceal grade } \\
2 \\
3 \\
4\end{array}$ & $\begin{array}{l}14(22 \cdot 2) \\
19(30 \cdot 2) \\
30(47 \cdot 6)\end{array}$ & $\begin{array}{l}12(11 \cdot 3) \\
41(38 \cdot 7) \\
53(50 \cdot 0)\end{array}$ \\
\hline \multicolumn{3}{|l|}{ Presenting complaint } \\
\hline $\begin{array}{l}\text { Jaundice } \\
\text { Haematemesis } \\
\text { Abdominal distension } \\
\text { Pedal oedema } \\
\text { Anorexia } \\
\text { Weight loss } \\
\text { Fever } \\
\text { Pain abdomen }\end{array}$ & $\begin{array}{r}8(12 \cdot 7) \\
22(34 \cdot 9) \\
20(31 \cdot 8) \\
4(6 \cdot 3) \\
6(9 \cdot 5) \\
2(3 \cdot 2) \\
1(1 \cdot 6)\end{array}$ & $\begin{array}{c}8(7 \cdot 5) \\
36(34 \cdot 0) \\
36(34 \cdot 0) \\
5(4 \cdot 7) \\
12(11 \cdot 3) \\
4(3 \cdot 8) \\
3(2 \cdot 8) \\
2(1 \cdot 9)\end{array}$ \\
\hline
\end{tabular}

${ }^{*} \mathrm{p}<0 \cdot 01 ; \nmid$ Figures in parentheses represent percentages.

and the age at diagnosis were found to be significantly higher in the adult, compared with the young cirrhotic group (Table 3 ).

\section{CLINICAL FEATURES AND COURSE}

The initial clinical presentation of the two groups of cirrhotic patients was similar (Table 1). The most common presenting symptoms were haematemesis and abdominal distension. There was no significant difference in the frequency of patients with different grades of oesophageal varices and Child's grade of liver disease between the two groups.

Table 2 Hepatitis B viral ( $H B V)$ markers in the two groups of cirrhotics*

\begin{tabular}{lcl}
\hline Parameter & $\begin{array}{l}\text { Young cirrhotics } \\
(n=63)\end{array}$ & $\begin{array}{l}\text { Adult cirrhotics } \\
(n=106)\end{array}$ \\
\hline HBs Ag+ve & $28(44 \cdot 5)$ & $39(36 \cdot 8)$ \\
Anti-HBs+ve & $4(6 \cdot 3)$ & $8(7 \cdot 5)$ \\
IgM anti-HBc+ve & $5(7 \cdot 9)$ & $4(3 \cdot 8)$ \\
HBV markers-ve & $23(36 \cdot 5)$ & $48(45 \cdot 3)$ \\
Status unknown & $3(4 \cdot 8)$ & $7(6 \cdot 6)$ \\
\hline
\end{tabular}

*There was no significant difference in the frequency of positive HBV markers between the two groups.
Table 3 Profile of alcoholic cirrhosis in the two groups of cirrhotics

\begin{tabular}{|c|c|c|c|}
\hline Parameter & $\begin{array}{l}\text { Young } \\
\text { cirrhotics } \\
(n=63)\end{array}$ & $\begin{array}{l}\text { Adult } \\
\text { cirrhotics } \\
(n=106)\end{array}$ & p Value \\
\hline Patients (n) & $11(17 \cdot 5 \%)$ & $31(29 \cdot 2 \%)$ & NS \\
\hline $\begin{array}{l}\text { Mean }( \pm S D) \text { age at start of } \\
\text { alcohol abuse (years) }\end{array}$ & $22 \cdot 1 \pm 5 \cdot 4$ & $32 \cdot 8 \pm 7 \cdot 3$ & - \\
\hline $\begin{array}{l}\text { Mean }( \pm S D) \text { duration of } \\
\text { alcohol consumption } \\
\text { (years) } \dagger\end{array}$ & $7 \cdot 1 \pm 4 \cdot 06$ & $13 \cdot 3 \pm 8 \cdot 7$ & $<0.01$ \\
\hline $\begin{array}{l}\text { Mean }( \pm S D) \text { amount }(g) \text { of } \\
\text { alcohol consumed/day }\end{array}$ & $137 \cdot 5 \pm 46 \cdot 9$ & $186 \cdot 9 \pm 50 \cdot 4$ & $<0.001$ \\
\hline $\begin{array}{l}\text { Mean }( \pm S D) \text { age at } \\
\text { diagnosis* }\end{array}$ & $29 \cdot 4 \pm 4 \cdot 1$ & $46 \cdot 5 \pm 9 \cdot 6$ & - \\
\hline
\end{tabular}

*Statistical analyses of these parameters are not presented as the patients in the two groups were preselected on the basis of differing ages; †non-parametric test used for statistical analysis.

The development of new symptoms during the course of the follow up of these patients showed no difference (Table 4), except for abdominal distension which occurred significantly $(p<0.05)$ more often in the adult cirrhotics. Signs of chronic liver disease were not different between the two groups, except for pedal oedema, which was seen significantly $(p<0.001)$ more often in the adult population.

FOLLOW UP, MORTALITY AND SURVIVAL

The mean follow up period from the time the patient first became symptomatic was $30 \cdot 6 \pm 29 \cdot 7$ months for the young and $25 \cdot 8 \pm 21.7$ months for the adult cirrhotics. There were $25(39.7 \%)$ deaths in the young and $47(44.3 \%)$ in the adult cirrhotic group during the follow up period (Table 5). In the adult group the majority $(63 \cdot 8 \%)$ of the patients died from terminal liver failure and only about one fourth $(25.6 \%)$ because of gastrointestinal bleeding. In the young cirrhotic group, almost equal number of patients died because of hepatic insufficiency $(40 \%)$ and variceal bleeding (52\%). The difference in the percentages of deaths from various causes between the two groups was not significant.

The majority $(59.6 \%)$ of the deaths in the adult cirrhotic group were limited to patients with Child's $\mathrm{C}$ grade of liver disease. On the other hand, in the young cirrhotics, nearly equal number of deaths occurred in Child's B and C category of liver disease (Table 5). While the only death in Child's A category in the young cirrhotic group was due to suicide committed by a young female patient by taking an overdose of barbiturate; in the adult group, the four deaths in the Child's A cirrhotics were the result of variceal bleeding in two, septicaemia in one and myocardial infarction in one patient. Here also, 
Table 4 Clinical profile of the two groups of cirrhotics during follow-up

\begin{tabular}{lccl}
\hline & $\begin{array}{l}\text { No }(\%) \text { of young } \\
\text { cirrhotics with } \\
\text { positive features } \\
(n=63)\end{array}$ & $\begin{array}{l}\text { cirrhotics with } \\
\text { positive features } \\
(n=106)\end{array}$ & $p$ Value \\
Parameter & $20(31 \cdot 7)$ & $21(19 \cdot 8)$ & NS \\
\hline Symptoms & $35(55 \cdot 6)$ & $64(60 \cdot 4)$ & NS \\
Jaundice & Haematemesis & $99(93 \cdot 4)$ & $<0 \cdot 05$ \\
Abdominal distension & $51(81 \cdot 0)$ & $13(12 \cdot 3)$ & NS \\
Pedal oedema & $7(11 \cdot 1)$ & $15(14 \cdot 2)$ & NS \\
Fever & $11(17 \cdot 5)$ & $15(14 \cdot 2)$ & NS \\
Anorexia & $7(11 \cdot 1)$ & $10(9 \cdot 4)$ & NS \\
Weight loss & $4(6 \cdot 4)$ & $29(27 \cdot 4)$ & NS \\
Hepatic Coma & $13(20 \cdot 6)$ & $6(5 \cdot 7)$ & NS \\
Past h/o jaundice & $8(12 \cdot 7)$ & & \\
Signs & & $40(37 \cdot 7)$ & NS \\
Jaundice & $28(44 \cdot 4)$ & $87(82 \cdot 1)$ & $<0 \cdot 001$ \\
Pedal oedema & $26(41 \cdot 3)$ & $51(48 \cdot 1)$ & NS \\
Abdominal veins & $(28(44 \cdot 4)$ & $91(85 \cdot 8)$ & NS \\
Ascites & $55(87 \cdot 3)$ & $50(47 \cdot 2)$ & NS \\
Hepatomegaly & $38(60 \cdot 3)$ & $61(57 \cdot 5)$ & NS \\
Splenomegaly & $37(58 \cdot 7)$ & $16(15 \cdot 1)$ & NS \\
Umbilical hernia & $7(11 \cdot 1)$ & & \\
\hline
\end{tabular}

the differences between the two groups were not significant.

The overall five year survival for the young $(61.9 \%)$ and the adult cirrhotic $(55.7 \%)$ population (Fig. 1) and the probability of survival, calculated until the end of follow up, was not different between the two groups (Fig. 2). There was no significant difference in the median survival time between the young (58.9 months) and the adult (35.9 months) cirrhotics. The median survival time for the combined group was 39.7 months. The probability of survival was not significantly related to sex and aetiology of cirrhosis (alcoholic $v$ non-alcoholic cirrhosis) in both young and adult groups. Survival was, however,

Table 5 Causes of death in the young and the adult cirrhotic patients

\begin{tabular}{llll}
\hline & $\begin{array}{l}\text { Young } \\
\text { cirrhotics } \\
(n=63)\end{array}$ & $\begin{array}{l}\text { Adult } \\
\text { cirrhotics } \\
(n=106)\end{array}$ & $p$ Value \\
\hline Total deaths & $25(39 \cdot 7)^{*}$ & $47(44 \cdot 3)$ & NS \\
Child's grade & $1(4 \cdot 0)$ & $4(8 \cdot 5)$ & \\
A & $13(52 \cdot 0)$ & $15(31 \cdot 9)$ & NS \\
B & $11(44 \cdot 0)$ & $28(59 \cdot 6)$ & \\
C & & & \\
Mode of death & $10(40 \cdot 0)$ & $30(63 \cdot 8)$ & NS \\
Terminal liver failure & $13(52 \cdot 0)$ & $12(25 \cdot 5)$ & \\
Gastrointestinal bleeding & - & $3(6 \cdot 4)$ & \\
Hepatoma & $2(8 \cdot 0)$ & $2(4 \cdot 3)$ & \\
Miscellaneous & & \\
\hline
\end{tabular}

${ }^{*}$ Figures in parentheses denote percentages.

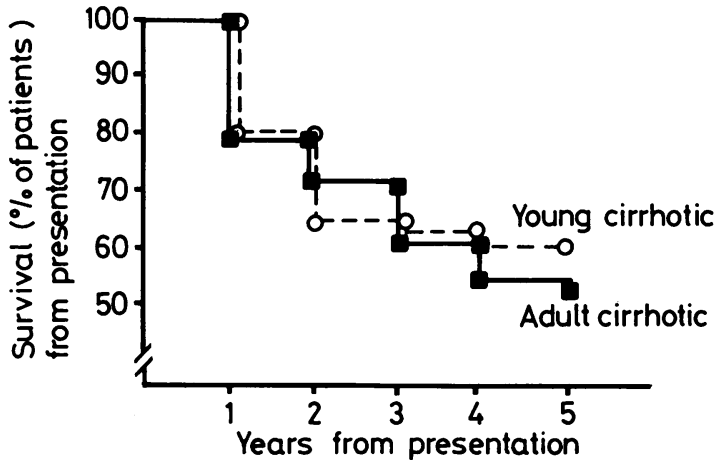

Fig. 1 Comparison of survival in young (O... $)$ ) and adult (日....) cirrhotics.

significantly influenced by the severity of liver disease in both the groups. The probability of survival was significantly higher in Child's A compared with Child's B and C and in Child's B as compared with Child's $C$ in both the groups of patients. However, within the same Child's grade of liver disease, survival was not related to the age group (Fig. 3).

\section{Discussion}

As $37 \%$ of the total cirrhotic population was 35 years or less in age, cirrhosis of liver is not uncommon in this age group. This figure would have been still higher if children below the age of 10 years had also been included. Our observations are supported by a recent study, in which $43 \%$ of all patients with cirrhosis were below the age of 35 years.' In another study by Keating et al from King's College Hospital, London, 83 young cirrhotics were seen within a period of 14 years. ${ }^{15}$ These observations are contrary

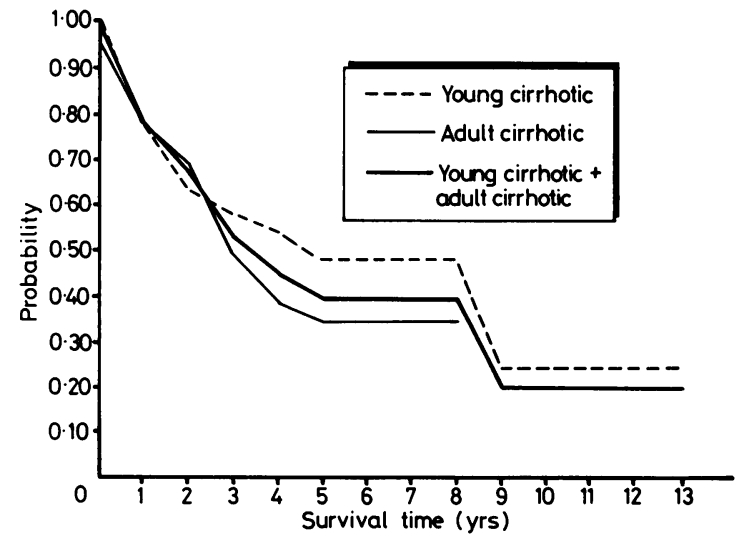

Fig. 2 Probability of survival of young (YC) and adult cirrhotics $(A C)$ and the combined $(Y C+A C)$ group. 


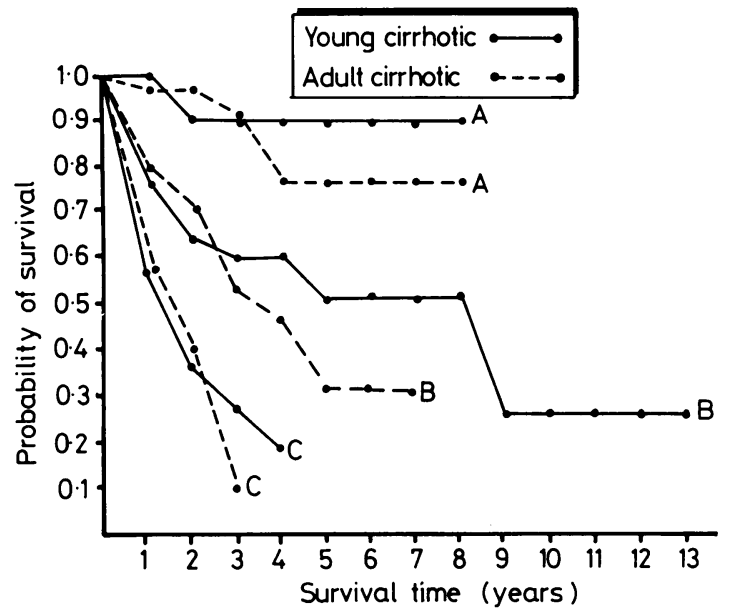

Fig. 3 Comparison of survival in patients with different Child's grade, in young (-_م) and adult (-...) cirrhotics.

to the findings of previous studies in which less than $5 \%$ of cirrhotics were reported to be under the age of 30 years. ${ }^{1-3}$

An important difference between our young and adult cirrhotic population was the strong male preponderance in the former. No clear explanation is available for the difference; though in an earlier study, the mean age of women with cirrhosis of liver was reported to be higher than men. ${ }^{3}$

The aetiology of cirrhosis did not differ in the young and adult cirrhotics. The diagnosis of HBV related cirrhosis was based on a positive $\mathrm{HBsAg}$ or anti-HBs test. The significance of positive anti-HBs in subjects with no evidence of chronic liver disease and patients with chronic liver disease is known to be different. Brechot et al have shown that $75 \%$ of patients with positive anti $\mathrm{HBs}$ and anti $\mathrm{HBc}$ have HBV DNA demonstrable in the liver. ${ }^{9}$ Presence of IgG anti $\mathrm{HBc}$ alone is also sufficient indication for HBV related chronic liver disease. However, only IgM anti $\mathrm{HBc}$ studies were carried out in our patients, which evaluate presence of recent HBV infection but do not necessarily suggest that $\mathrm{HBV}$ is responsible for the cirrhosis. Ben-Porath et al on the other hand, found no HBV DNA in the liver of anti HBs positive healthy subjects."

Unlike the situation in the West, ${ }^{1-1}$ alcoholic cirrhosis was seen only in men in both the groups. Similar observations have also been made in a recent study from North India. ${ }^{16}$ The absence of female alcoholic cirrhotics is mainly because of relatively rare and lesser alcohol abuse seen in women as against men in India. The social taboos probably also restrain women in India from seeking treatment for alcohol related problems. The mean age of alcoholic cirrhosis in our population of young cirrhotics was $29 \cdot 4 \pm 5 \cdot 1$ years; similar to the observations by Novick et al. ' The duration of alcohol consumption and the amount consumed per day were significantly less in the young compared with the adult cirrhotics. In a large study of more than 300 alcohol abusers consuming at least $130 \mathrm{~g}$ ethanol per day, Lelback found cirrhosis in only $8 \%$ of those drinking for 10 years or less. ${ }^{17}$ In the present study, the duration of alcohol consumption was less than 10 years in $11(26 \cdot 2 \%)$ patients; five young and six adult cirrhotics. While the exact mechanism is not clear, it is possible that genetic, environmental, and nutritional factors and possibly the type of liquor consumed by these patients may have predisposed them to an early development of cirrhosis. $1217 \mathrm{k}$

Indian childhood cirrhosis (ICC) is a relatively common disease in the Indian subcontinent and is characterised by onset in early childhood, ascites, jaundice, hepatosplenomegaly and a typical liver histology with generalised hepatocellular damage, creeping pericellular fibrosis, poor regeneration and quite often, deposits of Mallory's hyaline. ${ }^{1921}$ Although, a majority of patients present between one and three years of age, there are some controversial reports of ICC being documented in young adults. ${ }^{21}$ It is, therefore, important to look for ICC before giving a diagnosis of cryptogenic cirrhosis in a young adult. In the present study, however, no patient with ICC was identified.

Except for abdominal distension and pedal oedema which were seen more frequently in the adult cirrhotics, the presenting complaints and the clinical features during the follow up period in the two groups of patients were almost similar.

In the adult cirrhotics, nearly two thirds of the patients died because of terminal hepatic failure. In contrast, the frequency of patients dying because of hepatic failure and variceal bleeding was nearly the same in the young cirrhotics. The frequency of associated lesions like peptic ulcer or mucosal erosions as the cause of bleeding in patients with portal hypertension is very rare in India. ${ }^{2223}$ The observations of Keating et al where about $70 \%$ of young cirrhotics died because of liver failure and only $17 \%$ patients because of haematemesis, ${ }^{15}$ is quite at variance with our findings. Besides, a possible difference in the patient population ( $27 \%$ Child's $C$ in our series, compared with $45.8 \%$ in the study of Keating et al), the discrepancy could be because of the final criteria accepted for the mode of death. In the present study, we considered variceal bleeding as the cause of death, if it occurred soon before death and continued or led to hepatic coma and death.

This is probably the first prospective analysis in 
which the survival rate in the young and the adult cirrhotic population has been separately studied. The mean survival and the probability of survival did not differ between the young and the adult cirrhotics. In the study of Keating et al, the overall five year survival in young cirrhotics was reported to be $70 \%$; comparing more favourably with the survival rate in adult cirrhotics. ${ }^{15}$ An important drawback of this study, however, was that the young cirrhotics from King's College Liver Unit were compared with the data of adult cirrhotics from previous studies, ${ }^{1-3}$ which may not be a comparable population of patients. Moreover, a large proportion $(47 \%)$ of patients in this study had chronic active hepatitis, a condition which carries a much better (80-93\%) five years survival rate than cirrhosis. ${ }^{2425}$ When patients with cryptogenic cirrhosis were considered separately, the five year survival of young cirrhotics in the King's College study $(60 \%)$ compares well with our observations $(61.9 \%)$.

Prognostic significance of Child-Turcotte's classification has been recently reaffirmed. ${ }^{26}$ Severity of liver disease was found to strongly influence the survival in both young and adult cirrhotics, the survival in Child's A and B being significantly better than Child's $C$, and the survival in Child's A significantly better than Child's B patients. These observations are in contrast with the results of Keating et al who considered patients with Child's A and B class of cirrhosis as having good liver function with similar survival rates. ${ }^{15}$

There was no difference in the survival rate of patients with the same Child's grade of liver disease, between the young and the adult cirrhotics. The median survival time was also the same between men and women and alcoholic and non-alcoholic cirrhotics. In some studies limited to adult cirrhotics, however, male sex and alcoholic cirrhosis have been shown to be associated with a bad prognosis. ${ }^{27}$

It is concluded that cirrhosis is not uncommon in young adults under 35 years of age. The aetiology, initial clinical presentation, natural course of the disease, and the survival rate of young cirrhotics does not significantly differ from adult cirrhotics.

This study was partly supported by grants received from Indian Council of Medical Research.

\section{References}

1 Saunders JB, Walters JRF, Davies P, Paton A. A 20 year prospective study of cirrhosis. Br Med J 1981; 282: 263-6.

2 Creutzfeldt W, Belk K. Cirrhosis of the liver. On the etiology, pathogenesis, results of treatment and period of survival in an unselected series of 560 patients. Germ Med Mth 1966; 11: 259-65.
3 Stone WB, Islam NRK, Paton A. The natural history of cirrhosis: Experience with an unselected group of patients. QJ Med 1968; 37: 119-32.

4 Hallen J, Linne I. Cirrhosis of the liver in one community. In: Engel E, Larson T, eds. Alcoholic cirrhosis and other toxic hepatopathies. Stockholm: Nordiska Bokhandelrs Forlag, 1970: 336-55.

5 Garagliana CF, Lilienfold AM, Mendeloff AJ. Incidence rates of liver cirrhosis and related diseases in Baltimore and selected areas of United States. J Chronic Dis 1979; 32: 543-9.

6 Yoshida T, Kawata H, Fukui O, Koizumi T, Asada M, Wada M. Cirrhosis of the liver in Japan. Acta HepatoSplenol 1965; 12: 268-78.

7 Novick DM, Enlow RW, Gelb AM, et al. Hepatic cirrhosis in young adults: association with adolescent onset of alcohol and parenteral heroin abuse. Gut 1985; 26: 8-13.

8 Baposta A, Bianchi L, De-Groote J, et al. Alcoholic liver disease: Morphological manifestations. Lancet 1981; i: 707-12.

9 Brechot C, Degos F, Lugassy C, et al. Hepatitis $\beta$ virus DNA in patients with chronic liver disease and negative tests for hepatitis $\beta$ surface antigen. $N$ Engl J Med 1985; 312: 270-6.

10 Ben-Porath E, Hornstein L, Zeldis J, et al. Hepatitis $\beta$ virus infection and liver disease in Ethopian immigrants to Israel. Hepatology 1986; 6: 662-6.

11 Saunders JB, Wodak AD, Haines A, et al. Accelerated development of alcoholic cirrhosis in patients with HLA-B8. Lancet 1982; i: 1381-4.

12 Child CG, Turcotte JG. Surgery in portal hypertension. In: Child CG, ed. Major problems in clinical surgery: the liver and portal hypertension. Philadelphia: Saunders, 1964: 1-85.

13 Conn HO. Ammonia tolerance in the diagnosis of oesophageal varices. A comparison of the endoscopic, radiologic and biochemical techniques. J Lab Clin Med 1967; 70: 442-51.

14 Peto R, Pike MC, Armitage P, et al. Design and analysis of randomized clinical trials requiring prolonged observation of each patient. Br J Can 1977; 35: 1-39.

15 Keating JJ, Johnson RD, Johnson PJ, Williams R. Clinical course of cirrhosis in young adults and therapeutic potential of liver transplantation. Gut 1985; 26: 1359-63.

16 Roy K, Chawla LS, Sabharwal BD, Singh K, Whig J. Alcoholic liver disease in Punjab. Ind J Gastroenterol 1985; 4: 161-2.

17 Lelback WK. Quantitative aspects of drinking in alcoholic liver cirrhosis. In: Khanna JMH, Israel Y, Kalant J, eds. Alcoholic liver pathology. Toronto: Alcoholism and Drug Addiction Research Foundation of Ontario, Canada, 1975: 1-18.

18 Mezey E. Alcoholic liver disease. In: Popper $\mathbf{H}$, Schaffner F, eds. Progress in liver disease. Vol. VII. New York: Grune and Stratton 1982: 552-72.

19 Klass HJ, Kelly JK, Warnes TW. Indian Childhood cirrhosis in the United Kingdom. Gut 1980; 21: 344-50.

20 Mohan M, Bhargava SK, Sobti JC, Taneja PN. Indian Childhood cirrhosis - a heredo - familial disease. Indian Pediatr 1967; 4: 125-31. 
21 Parekh SR, Patel BD. Epidemiologic survey of Indian Childhood cirrhosis. Indian Pediatr 1972; 9: 431-9.

22 Sarin SK, Sachdev G, Nanda R. Follow-up after variceal eradication: a comparison of patients with cirrhosis, non-cirrhotic portal fibrosis and extra hepatic obstruction. Ann Surg 1986; 204: 78-82.

23 Anand CS, Tandon BN, Nundy S. The causes, management and outcome of upper gastro-intestinal haemorrhage in an Indian hospital. Br J Surg 1983; 70: 209-11.

24 Kirk AP, Jain S, Pocock S, et al. Late results of the Royal Free Hospital prospective controlled trial of prednisolone therapy in hepatitis $\beta$ surface antigen negative chronic active hepatitis. Gut 1980; 21 : 78-83.

25 Czaja AJ, Wolf AM, Summerskill WHJ. Development and early prognosis of oesophageal varices in severe chronic active liver disease (CALD) treated with prednisolone. Gastroenterology 1979; 77: 627-33.

26 Christensen E, Schlichting P, Fauerholdt L, et al. Prognostic value of Child-Turcotte criteria in medically treated cirrhosis. Hepatology 1984; 4: 430-5.

27 A report from the Copenhagen study group for liver disease; Sex, ascites and alcoholism in survival of patients with cirrhosis, effect of prednisolone. $N$ Engl J Med 1974; 291: 271-3. 